\title{
Assessment of EnKF Data Assimilation of Satellite Derived Soil Moisture Over the Indian Domain with the Noah Land Surface Model
}

\section{Vibin Jose}

Indian Institute of Space Science and Technology

Anantharaman Chandrasekar ( $\nabla$ chandatmos@gmail.com )

Indian Institute of Space Science and Technology

\section{Research Article}

Keywords: Data assimilation , Ensemble Kalman Filter (EnKF) , Noah, Advanced Scatterometer (ASCAT), Land Information System (LIS)

Posted Date: July 23rd, 2021

DOI: https://doi.org/10.21203/rs.3.rs-664035/v1

License: (c) (i) This work is licensed under a Creative Commons Attribution 4.0 International License.

Read Full License 


\title{
Assessment of EnKF data assimilation of satellite derived soil moisture over the Indian domain with the Noah Land Surface Model
}

\author{
Vibin Jose $^{1}$. Anantharaman Chandrasekar ${ }^{1 *}$
}

Received: date / Accepted: date

\begin{abstract}
Land Surface Models (LSMs) are typically forced with observed precipitation and surface meteorology and hence the soil moisture estimates obtained from LSM do not reflect the contribution of irrigation to the soil moisture estimates. However, the satellite retrievals of soil moisture estimates do register the signature of the irrigation effects. It is suggested that the soil moisture estimates obtained from LSM may reflect the role of irrigation if they are assimilated with soil moisture estimated from satellites.

The present study evaluates the improvement of soil moisture estimates obtained from Noah LSM by ingesting them with the satellite derived Advanced Scatterometer (ASCAT) soil moisture retrievals over the Indian domain for the year 2012. The above ingesting of soil moisture estimates is performed using the Land Information System (LIS). The improved soil moisture estimates are validated with the in-situ India Meteorological Department (IMD) soil moisture observations and also with the high-resolution Indian Monsoon Data Assimilation and Analysis (IMDAA) regional reanalysis data. The percentage of grid points over the Indian domain where the improvement parameter shows positive values are $59.14 \%$ (winter), $69.17 \%$ (pre-monsoon), $43.59 \%$ (monsoon), and $77.53 \%$ (post-monsoon). Furthermore, the forecast impact parameter also indicates the positive impact of data assimilation. Also, 12 of the 22 stations show reduced RMSE soil moisture error after data assimilation is performed while only 6 of the 22 stations show higher correlation coefficient in soil moisture without data assimilation, when validated with the in-situ IMD soil moisture observations. The study has also evaluated the irrigation impact of ASCAT in the assimilated soil moisture using triple collocation (TC) method. For the TC analysis, the model based Global Land Data Assimilation System (GLDAS)Catchment Land Surface Model (CLSM), and MERRA (Modern-Era Retrospective analysis for Research and Applications) Land data set together with soil moisture model outputs with and without ASCAT assimilation are used to calculate the error and correlation coefficient of each of the two set of triplets. The results of the TC analysis further conclusively shows the positive impact of irrigation effects in the ASCAT assimilated soil moisture model output.
\end{abstract}

* Corresponding Author:Anantharaman Chandrasekar

E-mail: chandra@iist.ac.in

${ }^{1}$ Department of Earth and Space Sciences, Indian Institute of Space Science and Technology, Valiamala P.O.,

Thiruvananthapuram - 695547 Kerala, India 
Keywords Data assimilation · Ensemble Kalman Filter (EnKF) - Noah, Advanced Scatterometer (ASCAT) $\cdot$ Land Information System (LIS)

\section{Introduction}

Soil moisture plays a vital role in the exchange of moisture and energy fluxes at the landatmosphere boundary. Hence, the accurate estimation of surface soil moisture is of utmost importance for various application studies such as the weather forecast, flood or drought prediction, soil erosion, and climate change (Walker and Houser. 2001).

Ground-based soil moisture observations are point observations and are limited in spatial and temporal extent and are expensive to maintain (Dorigo et al. 2011, Robinson et al., 2008). Land Surface Models (LSM) can provide for continuous and spatially distributed soil moisture estimates over a time period by integrating the LSM with appropriate atmospheric forcings. Regional and continental soil moisture estimates are entirely based on the output from LSM (Srinivasan et al. 2000). LSMs are usually forced with observed precipitation and surface meteorology and hence the soil moisture estimates obtained from LSM do not reflect the contribution of irrigation to the soil moisture estimates. However, the satellite retrievals of soil moisture estimates are effective in capturing the irrigation effects (Kumar et al. 2015: Nair and Indu, 2019). It is suggested that the soil moisture estimates obtained from LSM may reflect the role of irrigation if they are assimilated with soil moisture estimated from satellites (Kumar et al., 2015). Furthermore, the above assimilation would contribute to reduced uncertainties in the LSM soil moisture estimates to ultimately yield a much improved soil moisture estimate. Although such studies that ingest soil moisture obtained from LSM with satellite retrievals exist in the literature (Kumar et al. 2015, Nair and Indu. 2019), there are very few instances where such studies have been carried out over India.

Ensemble Kalman Filter (EnKF) technique is widely employed in data assimilation for the following reasons (i) the suitability of its sequential structure for processing the satellite retrievals in real time, (ii) its easy implementability even with nonlinear model equations, and (iii), its ability to consider a number of model errors (Reichle et al. 2002). Blankenship et al. (2016) assimilated the Soil Moisture and Ocean Salinity (SMOS) satellite retrieval into the Noah Land surface states via EnKF and showed that the anomaly correlation of soil moisture at $10 \mathrm{~cm}$ depth has increased from 0.45 to 0.57 with respect to in-situ measurements over the central and southeastern United States. Nair and Indu (2016) studied the improvement of Noah LSM soil moisture by assimilating Soil Moisture Operational Products System (SMOPS) satellite soil moisture over the Indian domain and showed an improvement in the results with the values of average correlation of 0.96 and average root mean square difference of $0.03 \mathrm{~m}^{3} \mathrm{~m}^{-3}$. Drusch (2007) studied the impact of data assimilation on the European Centre for Medium-Range Weather Forecasts (ECMWF) integrated forecast system using Tropical Rainfall Measuring Mission (TRMM) Microwave Imager (TMI) soil moisture data set.

The main objective of this study is to examine, whether the LSM soil moisture estimates after assimilation, do reflect the contribution of irrigation considering that India is a reasonably well irrigated country. Towards realizing the above objective, an attempt is made to improve the LSM soil moisture estimates by assimilating Advanced Scatterometer (ASCAT) satellite soil moisture retrievals into the Noah LSM using an EnKF technique. Furthermore, a detailed validation of the improved near surface soil moisture estimate is performed by comparing the assimilated land surface state with in-situ ground based weekly 


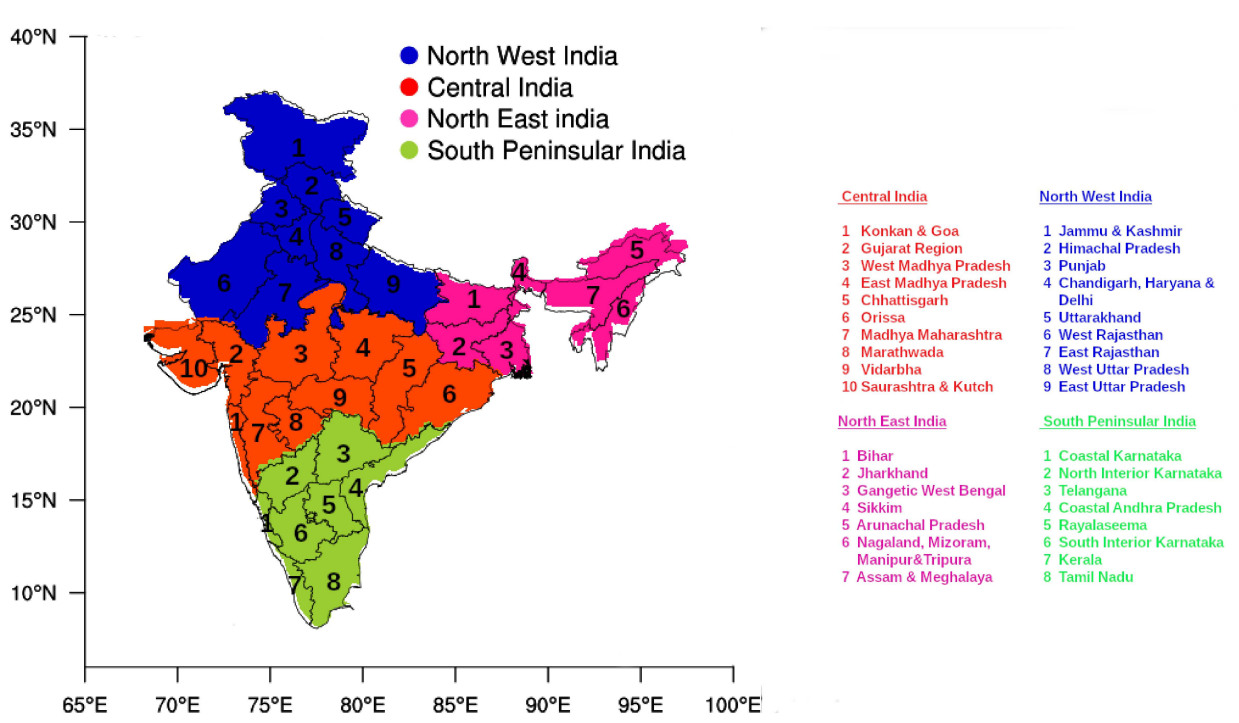

Fig. 1: The homogeneous regions, numbering four defined by India Meteorological Department (IMD) are based on the amount of precipitation as well as the seasonal variations of precipitation. Also, the various meteorological subdivisions within each of the four homogeneous regions of India are defined by IMD

India Meteorological Department (IMD) observations as well as with the high-resolution Indian Monsoon Data Assimilation and Analysis (IMDAA) regional reanalysis data sets. For IMDAA, the soil moisture analysis is produced by applying Extended Kalman Filter (EKF) based land data assimilation system by ingesting (ASCAT soil wetness from MetOp satellite) soil moisture observations. Since the above mentioned high resolution IMDAA soil moisture analysis is obtained by assimilating satellite soil moisture estimates, the above will have the signature of the irrigation.

\section{Model, Simulation and Validation}

\subsection{Land Information System (LIS)}

The present study employs 3.6 version of Noah LSM (Mitchell et al., 2004) available within the National Aeronautics and Space Administration (NASA) LIS (Kumar et al. 2006) that provides for EnKF data assimilation technique. The Noah LSM is based on the coupling of the diurnally dependent Penman potential evaporation approach of Mahrt and Ek (1984), the multi layer soil model of Mahrt and Pan (1984), and the primitive canopy model of Pan and Mahrt (1987). The above LSM has been extended by Chen et al. (1996) to include the effects of canopy resistance using the approach of Noilhan and Planton (1989) and Jacquemin and Noilhan (1990). The Noah LSM has one canopy layer and four soil layers with thickness of each layer from the ground surface being $0.1,0.3,0.6$, and $1.0 \mathrm{~m}$, respectively with the following prognostic variables such as soil moisture and temperature in the soil layers, water stored on the canopy, and snow stored on the ground. While the root zone is in the upper $1 \mathrm{~m}$ of soil, the lowest $1 \mathrm{~m}$ soil layer acts like a reservoir with a gravity drainage 
at the bottom. The surface skin temperature is determined following Mahrt and Ek (1984) by applying a single linearized surface energy balance equation representing the combined ground-vegetation surface with the ground heat flux determined by the diffusion equation for soil temperature. The prognostic equation for the volumetric soil moisture content is determined by the Richard diffusion equation which is derived from Darcy's law under the assumption of a rigid, isotropic, homogeneous, and one-dimensional vertical flow domain. The Noah LSM has a simple snow and sea-ice model; the snow model has a single layer of snow cover and simulates the snow accumulation, sublimation, melting, and heat exchange at snow-atmosphere and snow-soil interfaces. The precipitation is categorized as snow when the temperature in the lowest atmospheric layer is below $0^{\circ} \mathrm{C}$. The Noah LSM employs the vegetation type and soil texture as the two primary variables upon which other secondary parameters such as minimal canopy resistance and other soil hydraulic properties are determined. More details are available from Chen and Dudhia (2001).

The Noah LSM is forced with meteorological forcings and land surface parameters. For the present study, the land cover data is obtained from the Moderate Resolution Imaging Spectroradiometer-International Geosphere-Biosphere Programme (MODIS-IGBP), with a horizontal resolution of $1 \mathrm{~km}$. State Soil Geographic-Food and Agriculture Organization (STATSGO-FAO) blended soil texture map data provides the soil texture data set for this study. Shuttle Radar Topography Mission (SRTM) data is used for elevation. The monthly albedo, maximum snow albedo, Greenness fraction and Slope type data sets are obtained from corresponding NCEP data sets with a spatial resolution of $0.01^{\circ} \times 0.01^{\circ}$. Bottom temperature information is taken from the International Satellite Land Surface Climatology Project 1 (ISLSCP1) bottom temperature data sets. The meteorological forcing data is taken from Global Data Assimilation System (GDAS) except for the rainfall rate which is from IMD gridded rainfall data with a spatial resolution of $0.25^{\circ} \times 0.25^{\circ}$.

Soil moisture is an important variable, that needs to be initialized accurately. For the present study, the Noah LSM was spun-up by cycling five times (five loops) through the period from 01 January 201100 UTC to 01 January 201200 UTC using all the meteorological forcing data from GDAS and rainfall data from IMD. The deepest soil layer $(0.60$ $\mathrm{m}$ to $1 \mathrm{~m}$ ) soil moisture content in the Noah LSM is utilized for assessing the establishment of the equilibrium condition by checking and ensuring that the differences between the soil moisture content at the deepest layer for the present and the previous loop is less than 5\% (Case et al., 2007; Rodell et al., 2005).

The study area is over the Indian land domain spanning a latitude ranging from $6.375^{\circ} \mathrm{N}$ to $38.375^{\circ} \mathrm{N}$ and a longitude encompassing from $66.375^{\circ} \mathrm{E}$ to $99.875^{\circ} \mathrm{E}$ with a horizontal resolution of $0.125^{\circ} \times 0.125^{\circ}$. In this study, the Indian landmass domain is divided into four homogeneous regions namely, Northwest India, Northeast India, Central India, and South Peninsular India according to the distribution of monsoon rainfall over the Indian domain. The four homogeneous regions and their meteorological subdivisions are shown in Figure 1

\subsection{ASCAT and LIS simulation}

ASCAT is a real aperture radar system carried on-board the Meteorological Operational (Metop) polar satellites launched by the European Space Agency (ESA) which provides day-night measurements unaffected by cloud cover. The surface soil moisture estimated from ASCAT for the topmost soil layer $(<5 \mathrm{~cm})$ is given in degree of saturation, ranging 
Table 1: Summary of Perturbations

\begin{tabular}{|c|c|c|c|c|c|c|c|}
\hline & \multirow[t]{2}{*}{ Variable } & \multirow[t]{2}{*}{$\begin{array}{l}\text { Perturbation } \\
\text { type }\end{array}$} & \multirow[t]{2}{*}{$\begin{array}{l}\text { Standard } \\
\text { deviation }\end{array}$} & \multicolumn{4}{|c|}{$\begin{array}{l}\text { Cross } \\
\text { Correlation }\end{array}$} \\
\hline & & & & SW & LW & $\mathrm{P}$ & NST \\
\hline \multirow{6}{*}{ Forcing } & Short Wave (SW) & Multiplicative & $0.2\left(\mathrm{Wm}^{-2}\right)$ & 1 & -0.3 & -0.5 & 0.3 \\
\hline & Long Wave (LW) & Additive & $0.3\left(\mathrm{Wm}^{-2}\right)$ & -0.3 & 1 & 0.5 & 0.6 \\
\hline & Precipitation $(\mathrm{P})$ & Multiplicative & $0.5(\mathrm{~mm})$ & -0.5 & 0.5 & 1 & -0.1 \\
\hline & Near Surface & Additive & $0.5(\mathrm{~K})$ & 0.3 & 0.6 & -0.1 & 1 \\
\hline & Temperature (NST) & & & & & & \\
\hline & Soil Moisture & & & L1 & L2 & L3 & L4 \\
\hline \multirow{4}{*}{$\begin{array}{l}\text { State } \\
\text { variable }\end{array}$} & Layer 1 (L1) & Additive & $6.00 \times 10^{-3} \mathrm{~m}^{3} \mathrm{~m}^{-3}$ & 1 & 0.6 & 0.4 & 0.2 \\
\hline & Layer 2 (L2) & Additive & $1.10 \times 10^{-4} \mathrm{~m}^{3} \mathrm{~m}^{-3}$ & 0.6 & 1 & 0.6 & 0.4 \\
\hline & Layer 3 (L3) & Additive & $6.00 \times 10^{-5} \mathrm{~m}^{3} \mathrm{~m}^{-3}$ & 0.4 & 0.6 & 1 & 0.6 \\
\hline & Layer 4 (L4) & Additive & $4.00 \times 10^{-5} \mathrm{~m}^{3} \mathrm{~m}^{-3}$ & 0.2 & 0.4 & 0.6 & 1 \\
\hline Observation & ASCAT & Additive & $0.04 \mathrm{~m}^{3} \mathrm{~m}^{-3}$ & & & & \\
\hline
\end{tabular}

from $0 \%$ (dry) to $100 \%$ (wet) and are available with a resolution of $0.25^{\circ} \times 0.25^{\circ}$ on daily intervals. In this study, ASCAT data is obtained from SMOPS(Liu et al., 2012).

Two simulations are performed to evaluate the positive impact of assimilation of daily ASCAT soil moisture retrievals with the Noah LSM land surface states; (i) control run (CNTRL run) with no assimilation and (ii) assimilation run using EnKF (EXP run). The Noah LSM is integrated from 01 January 201200 UTC to 31 December 201200 UTC. The ENKF data assimilation algorithm has a sequential approach having the two following steps, (i) a forecast step, and (ii) an update step. EnKF method utilized thirty ensemble members, obtained from perturbations on meteorological forcing, model estimated states, and observations. The details of perturbations that represent the uncertainty in the land surface conditions are given in Table 1 and are based on study by (Yin et al. 2015). The 30 ensembles are generated by applying random Gaussian error with zero mean. Values of cross correlation in perturbation of near soil temperature (NST), Precipitation, and radiation fields (Short Wave(SW) and Long Wave(LW)) are shown in Table 1 The ASCAT soil moisture observations are perturbed with random Gaussian noise with a standard deviation of $0.04 \mathrm{~m}^{3} \mathrm{~m}^{-3}$ (Nair and Indu, 2019).

Data assimilation theory requires both unbiased observation and unbiased model states. However, there are large differences between the temporal moments of the model and the satellite retrievals. Hence, the present study accounted for the bias correction using the cumulative distribution function (CDF) matching technique (Reichle and Koster, 2004).

\subsection{IMDAA regional reanalysis data and IMD in-situ data}

High resolution soil moisture data both at near surface as well as at three depths $(0-0.1 \mathrm{~m}$, 0.1-0.35 m, 0.35-1 m, and 1-3 m) are available from the Indian Monsoon Data Assimilation and Analysis (IMDAA) re-analysis (Ashrit et al. 2020). The IMDAA soil moisture reanalysis data is available at every hour and with a horizontal resolution of $12 \mathrm{~km}$ over the domain spanning latitude from $-15^{\circ} \mathrm{S}$ to $45^{\circ} \mathrm{N}$ and longitude from $30^{\circ} \mathrm{E}$ to $120^{\circ} \mathrm{E}$. The IMDAA system with 63 vertical levels is based on the Met Office four-dimensional variational data assimilation (4DVAR) and its Unified Model, and uses a 6 hour intermittent data assimilation cycle. Lateral boundary conditions for the reanalysis run are taken from the global reanalysis (ECMWF Re-Analysis) ERA-Interim. The following observations are 


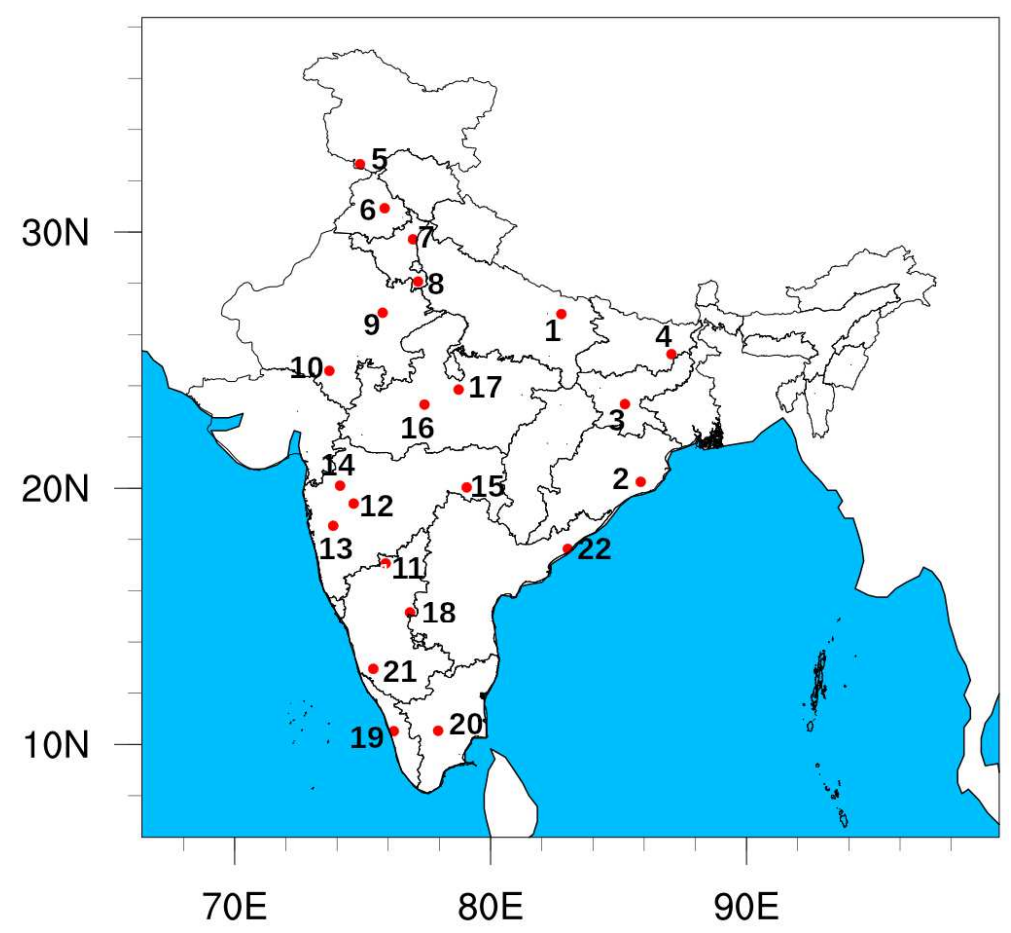

Fig. 2: IMD in-situ Station locations as numbered in Table 2 .

assimilated in the 4DVAR system, (i) Surface observations, (ii) Upper air, (iii) Aircraft, (iv) Atmospheric motion vector from Geostationary Meteorological Satellite-4, and (v) TOVS (Microwave Sounding Unit (MSU) and High-resolution Infrar Red Sounder (HIRS)) satellite radiances.

IMD in-situ soil moisture data from 22 stations are utilized in this study to validate the improved soil moisture estimates obtained from the EnKF data assimilation for the year 2012. The in-situ data are available every week at different depths $(0 \mathrm{~m}, 0.075 \mathrm{~m}, 0.15 \mathrm{~m}$, $0.30 \mathrm{~m}, 0.45 \mathrm{~m}$, and $0.60 \mathrm{~m}$ ). The IMD in-situ station locations are shown in Figure 2

\subsection{Validation}

The quantitative evaluation of the assimilated soil moisture with respect to IMDAA data is calculated using an improvement parameter and a forecast impact parameter. Improvement parameter is defined as

$$
\eta=\left|\mathrm{SM}_{\mathrm{obs}}-\mathrm{SM}_{\mathrm{CNTRL}}\right|-\left|\mathrm{SM}_{\mathrm{obs}}-\mathrm{SM}_{\mathrm{EXP}}\right|
$$

where $\mathrm{SM}_{\mathrm{obs}}, \mathrm{SM}_{\mathrm{CNTRL}}$, and $\mathrm{SM}_{\mathrm{EXP}}$ refer to surface soil moisture that is obtained from IMDAA, and from CNTRL and EXP runs. The positive value of improvement parameter 
' $\eta$ ' is a measure of the positive improvement of the soil moisture estimate due to EnKF data assimilation.

The forecast impact (FI) parameter is defined as

$$
F I=\left(1-\frac{R M S E(E)}{R M S E(C)}\right) \times 100
$$

where RMSE (E) and RMSE (C)are the Root Mean Square Error (RMSE) of the EXP and CNTRL runs soil moisture data (at $5 \mathrm{~cm}$ depth) with respect to the IMDAA data. The positive value of the FI parameter indicates the positive impact of soil moisture data assimilation.

A two-sample Kolmogorov-Smirnov distance (KS-D) (Chakravarty et al., 1967) statistical test is used in this study to quantitatively compare the probability distribution between the CNTRL and EXP run. It is based on a null hypothesis that the two sample distributions (CNTRL and EXP) are taken from the same source distribution. The KS-D value gives the empirical difference between the two sample distributions.

\subsection{Evaluation using Triple Collocation (TC) method}

The present study employed the TC method to evaluate the irrigation impact of ASCAT in the assimilated soil moisture. The basic idea of this approach is to obtain the unknown error standard deviations of three independent (it is assumed that the errors are uncorrelated) measurements, without the knowledge of the truth [Stoffelen (1998)]. Initially, the TC method was widely employed in oceanographic studies to evaluate the errors in sea surface temperature measurements (Gentemann 2014; O'Carroll et al., 2007). Subsequently, it has been applied in soil moisture studies (Nair and Indu. 2019). In order to ensure that the errors of the three measurements remain uncorrelated, the present study has utilized soil moisture obtained from Global Land Data Assimilation System (GLDAS)Catchment Land Surface Model (CLSM), and MERRA (Modern-Era Retrospective analysis for Research and Applications) Land data set along with the CNTRL run for the TC analysis. Furthermore, TC analysis is also performed on the soil moisture obtained from GLDAS CLSM and MERRA data along with the EXP run. The above mentioned approach will be able to evaluate the irrigation impact of ASCAT in the assimilated soil moisture with the same reference since the first two data sets (GLDAS CLSM and MERRA) remain the same in each of three independent data sets.

\section{Results and discussion}

Figure 3 shows the spatial distribution of improvement parameter for different seasons during the year 2012 at $5 \mathrm{~cm}$ depth. The percentage of grid points over land where the improvement parameter is positive with respect to the total number of grid points is named ' $\alpha$ ' and the values of ' $\alpha$ ' for the winter (January-February), pre-monsoon (March-May), southwest monsoon (June-September), and post-monsoon (October-November) seasons are $59.14 \%, 69.17 \%, 43.59 \%$, and $77.53 \%$ respectively. For the south-west monsoon season, the percentage of improvement parameter is slightly less than $50 \%$. It is well known that Noah LSM's soil moisture estimate is completely devoid of any effects of irrigation while the satellite derived soil moisture does register the signature of the irrigation effects. Also the IMDAA soil moisture has the signature effects of irrigation. It is well known that India as a whole receives as much as $80 \%$ of its annual rainfall during its south-west monsoon 

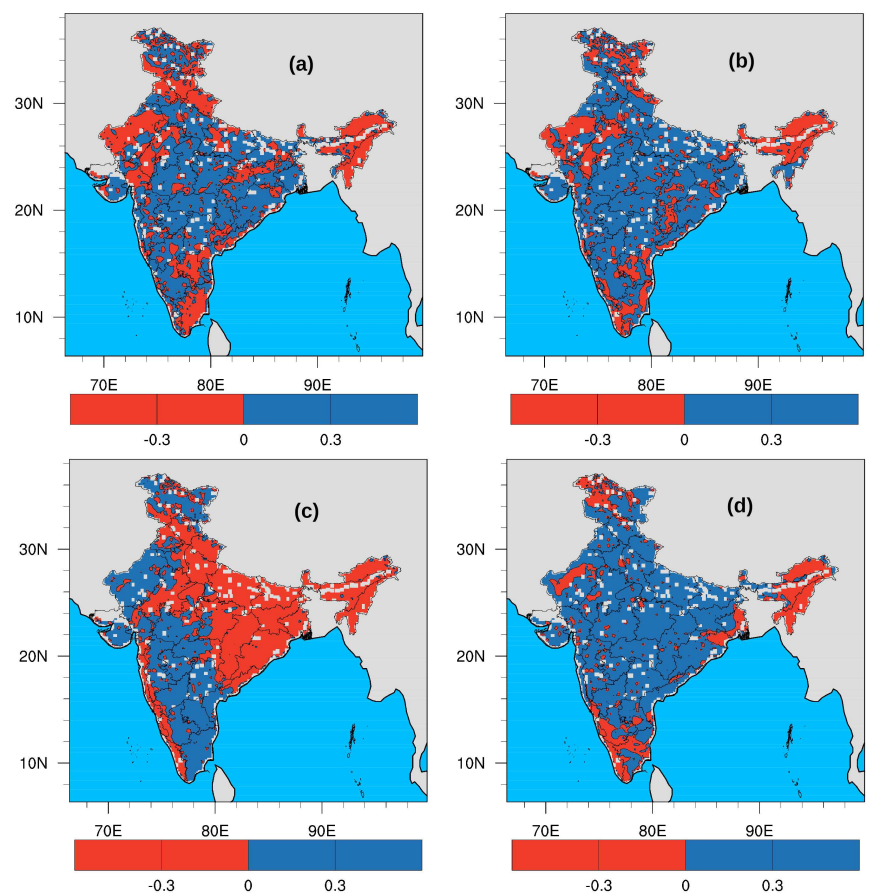

Fig. 3: The spatial distribution of improvement parameter for the year 2012, where a, b, c, d represents winter, pre-monsoon, monsoon, and post-monsoon respectively.

season lasting four months. The monsoon season being the rainy season, the requirement of irrigation of the same magnitude and extent becomes less for India during the monsoon season as compared to the other three seasons. Keeping the above in mind, the results of Figure 3. that reveal the lack of extensive regions of improvement in the soil moisture estimates due to ingestion of satellite derived soil moisture (the latter incorporating the irrigation effects) during the monsoon season are not surprising.

Figure 4 shows the spatial distribution of the forecast impact parameter for the year 2012 at $5 \mathrm{~cm}$ depth. The percentage of grid points over land where the forecast impact parameter is positive with respect to the total number grid points is named ' $\beta$ ' and the values of ' $\beta$ ' for winter, pre-monsoon, southwest monsoon, and post-monsoon seasons are $58.43 \%, 69.26 \%$, $45.85 \%$, and $75.66 \%$ respectively. The southwest monsoon season has a lower percentage of grid points having requirement of irrigation during the southwest monsoon season.

The resulting values for the K-S distance(D) for different seasons are shown in Figure 5 When the K-S-D value is close to zero, the above indicates that the CNTRL and EXP run soil moisture distributions are similar. Contrarily, larger values of K-S-D suggests that the differences between the probability distribution of CNTRL and EXP integrations are marked. The presence of regions having large values of K-S-D may be attributed to the impact of irrigation over the above regions.

Figures $6 \mathrm{a}-6 \mathrm{~d}$ depict the difference in near surface soil moisture between ASCAT and CNTRL run for different seasons (winter, pre-monsoon, monsoon, and post-monsoon) of 2012. India, as a whole had near normal annual rainfall (-11\% departure with respect to normal), with the monsoon season receiving $78 \%$ of annual rainfall with a $-7 \%$ departure of its 

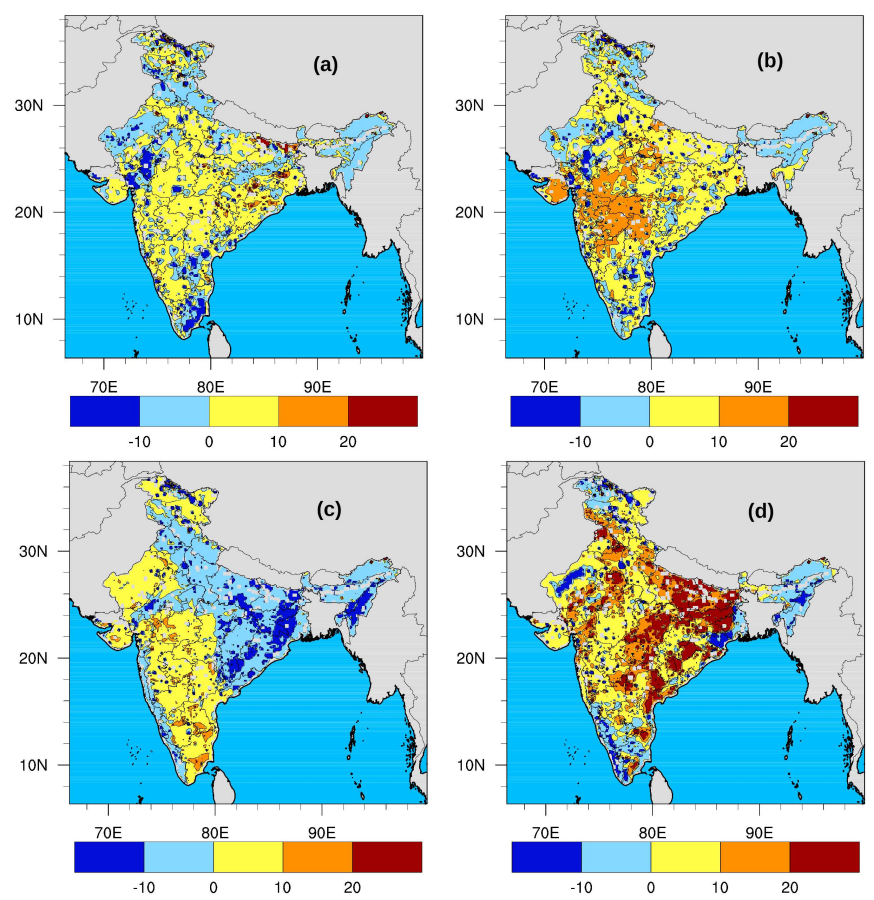

Fig. 4: The spatial distribution of forecast impact parameter for the year 2012, where a, b, c, $\mathrm{d}$ represents winter, pre-monsoon, monsoon, and post-monsoon respectively.

monsoon rainfall. Figure 6 shows that the differences in the soil moisture are quite small during the winter season. The winter season has the least amount of rainfall (3.7\% of annual rainfall) and hence the soil moisture values from ASCAT are not high. With the CNTRL run overestimating soil moisture values as compared to IMDAA, it is not surprising that CNTRL soil moisture values are higher than ASCATs. The lack of marked differences between ASCAT and CNTRL soil moisture values would result in lack of pronounced positive impact due to EnKF data assimilation, as reflected in Figures 3 and 4 a.

Figure 6p shows that the differences in the soil moisture in pre-monsoon season is marked and has negative values over Madhya Maharashtra, Marathwada, Vidarbha, Saurashtra and Kutch (all part of central India) and also over Telangana and North Interior Karnataka (part of South Peninsular India). Most of the above mentioned regions have experienced deficit rainfall during pre-monsoon season with percentage departures ranging from $-40 \%$ (Madhya Maharashtra) to -94\% (Saurashtra and Kutch) (Kaur and Purohit, 2013) and these regions contain mostly non irrigated croplands as compared to other homogeneous regions (Figure 3 of Ambika et. al (Krishnankutty Ambika et al., 2016)) leading to lower soil moisture as estimated by ASCAT. With the overestimation of CNTRL soil moisture, the difference between ASCAT and CNTRL run is markedly negative in the above regions. The above-mentioned regions also have the largest positive FI values during the pre-monsoon season (refer Figure 4p). The above result reveals that the overestimation of CNTRL soil moisture has reduced in the EXP run, resulting in positive impact, when the LSM is assimilated with ASCAT soil moisture. 

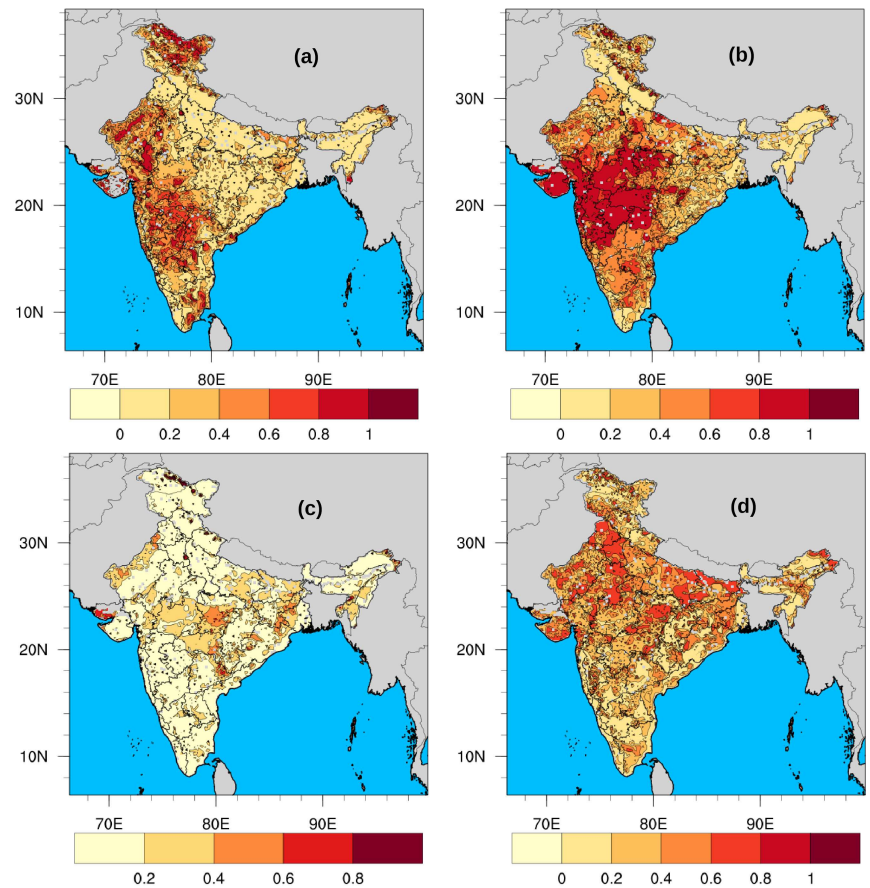

Fig. 5: KolmogorovSmirnov distance (D) from comparison of soil moisture distributions from CNTRL and EXP integrations for the year 2012 where a, b, c, d represents winter, pre-monsoon, monsoon, and post-monsoon respectively.

Figure 65 shows that the differences in the soil moisture in the monsoon season are quite small and have mostly positive values except for regions over Tamil Nadu, South Interior Karnataka, North Interior Karnataka (all part of South Peninsular India), Saurashtra and Kutch, and Gujarat (part of Central India). Most parts of India received normal rainfall during the monsoon season ( $78 \%$ of annual rainfall) in 2012, increasing the soil moisture estimates from ASCAT and contributing to positive differences in soil moisture between ASCAT and CNTRL run. A few regions, however, received lower rainfall with percentage departure during monsoon season being $-23 \%$ for Tamil Nadu and South Interior Karnataka, $-36 \%$ for North Interior Karnataka, $-34 \%$ for Saurashtra and Kutch and $-28 \%$ for Gujarat region (Kaur and Purohit, 2013). Lower rainfall over these regions contributed to lower soil moisture and hence differences between ASCAT and CNRL soil moisture became negative over these regions. However, the magnitude of the decrease (i.e. large negative differences as seen during the pre-monsoon season) is considerably reduced during the monsoon season. Figure 47 shows that the above regions show a marginal impact of EnKF data assimilation while the K-S-D values are also close to zero over these regions during the southwest monsoon season (Figure 5r).

Figure 6d shows that the differences in the soil moisture is quite small during the postmonsoon season. Figure $6 \mathrm{~d}$ is similar to Figure 6 a except that for the post-monsoon case, the ASCAT soil moisture has higher soil moisture values over more regions than the CNTRL run as compared to the winter season. The above can be explained by considering that the postmonsoon follows the monsoon season with the latter contributing $78 \%$ of the annual rainfall 

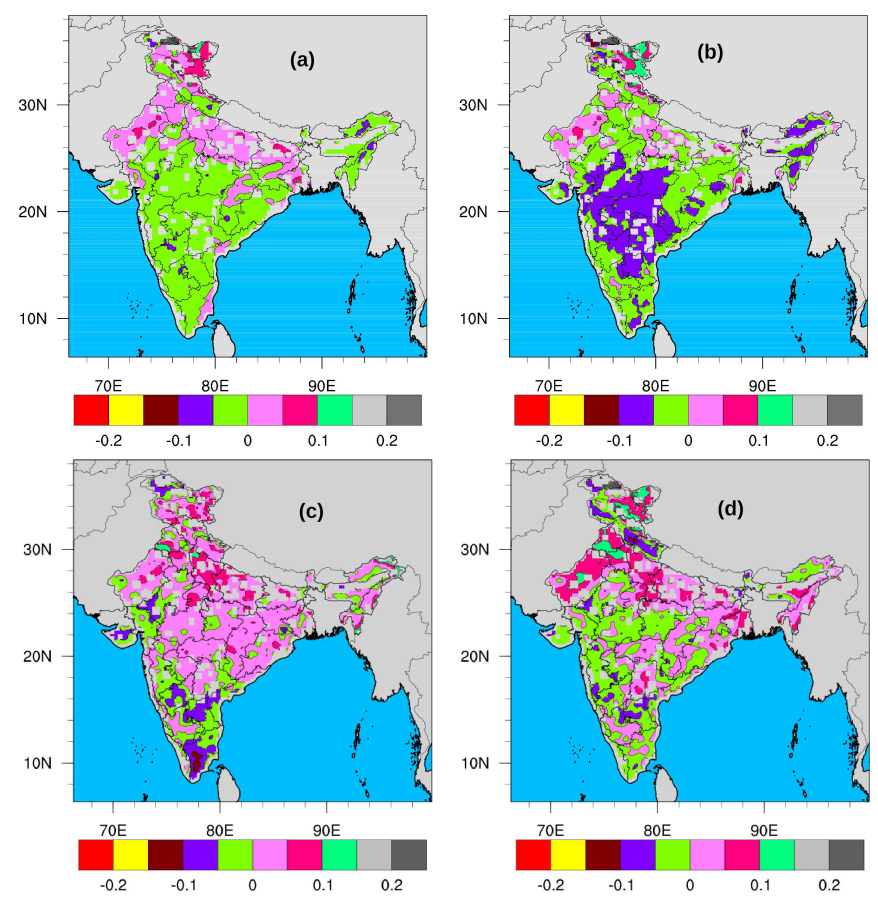

Fig. 6: The spatial distribution of bias between the ASCAT soil moisture and CNTRL run soil moisture for different seasons for the year 2012, where a, b, c, d represents winter, pre-monsoon, monsoon, and post-monsoon respectively.

with the year 2012 having only $-7 \%$ departure of rainfall during the monsoon season. With such good rain over most parts of India, one would expect the ASCAT soil moisture values to be higher than the CNTRL run values. Figure $4 \mathrm{~d}$ shows that the maximum positive FI values during the post-monsoon season are seen over Bihar, Gangetic West Bengal, Jharkhand (all part of North East India) as well as Chattisgarh, Orissa, (part of Central India) and coastal Andhra Pradesh (part of South Peninsular India). It is pertinent to note from Figure 6d, that the above mentioned regions had positive soil moisture difference values. Although the highest positive FI values are observed in post-monsoon season (refer Figure $4 \mathrm{~d}$ ), it is clear that the maximum K-S-D values are seen in the pre-monsoon season (Figure $5 \mathrm{p}$ ), the latter consistent with the maximum differences between ASCAT and CNTRL values of soil moisture during the pre-monsoon season (refer Figure 6p).

Tables 2 to 6 show the soil moisture RMSE and correlation coefficient of CNTRL run, EXP run, and IMDAA with respect to IMD in-situ soil moisture data for 22 stations at $5 \mathrm{~cm}$ depth for different seasons (Table 3 to 6) and the annual average for the year 2012 ( Table2). It is clear from Table 2 that only 9 stations from the total 22 stations show a lack of improvement due to EnKF data assimilation (RMSE (CNTRL) is lower than RMSE (EXP)). The above clearly indicates that the positive benefits of EnKF data assimilation (12 of the 22 stations show lower RMSE of soil moisture after assimilation) are observed over a majority of the IMD soil moisture stations. Out of 22 stations, 11 stations show higher correlation coefficient values due to EnKF data assimilation, while 5 stations show 
no change in correlation coefficient value due to assimilation. The remaining 6 stations show lower correlation coefficient values after data assimilation.

The irrigation map of India for the year 2012 is shown in Figure $7 \mathrm{~d}$ (Devanand et al. 2019). The above figure shows that the most irrigated areas are observed over the IndoGangetic plain while least irrigated areas are seen over the south western region of India. Table 7 has tabulated the 22 IMD in-situ stations into three classes namely, a low irrigated $(<6 \mathrm{~mm}$ ), moderately irrigated (6 to $14 \mathrm{~mm}$ ), and highly irrigated (above $14 \mathrm{~mm}$ ) based on Figure $7 \mathrm{~d}$. Three of the highly irrigating stations such as Basti, Ranchi, and Solapur have shown positive impact due to the assimilation of ASCAT soil moisture in terms of lower RMSE of soil moisture of the EXP run as compared to CNTRL run (refer Tables 2 to 6 ). Since the ASCAT soil moisture values have a signature of irrigation effects (Nair and Indu. 2019, Zhang et al. 2018), one would expect that over highly irrigated regions, assimilation of ASCAT soil moisture would result in much-improved estimates closer to the ground truth after data assimilation. The above hypothesis is confirmed with lower RMSE values of EXP run as compared with CNTRL run for each of the four seasons as well as for the annual average. Another highly irrigated station, Karnal show the same RMSE values of soil moisture before and after assimilation (refer Table 2), indicating that there is no degradation of the soil moisture estimates after data assimilation.

Among the 11 moderately irrigated stations, seven of the stations (Bhubaneswar, Ludhiana, Durgapura, Sagar, Bellari, Chatha, and Vedasundar) have shown positive impact due to the assimilation of ASCAT soil moisture in terms of lower RMSE of soil moisture of the EXP run as compared to CNTRL run. It is clear that the above mentioned moderately irrigated stations have shown improvement in soil moisture estimates after assimilation of ASCAT soil moisture, the latter having the signature of irrigation. It is pertinent to note that irrespective of rainfall received that includes stations receiving below normal rainfall (departure of annual rainfall from normal for Bellari is $-13 \%$, for Bhubaneswar is $-17 \%$, for Sagar is $-23 \%$ ) or receiving normal rainfall (Durgapura, Jaipur district has $10 \%$ departure of annual rainfall from normal and Chatha, Jammu district has 5\% departure) or receiving deficit rainfall (Vedasundar, Dindigul district has $-32 \%$ departure of annual rainfall from normal and Ludhiana has $-55 \%$ departure), all these seven moderately irrigated stations have shown positive impact. Two other moderately irrigated stations (Anakapalle and New Delhi) have a very small difference in the RMSE of soil moisture before and after ASCAT soil moisture assimilation (0.007 and 0.001).

One would expect a negative impact due to the assimilation of ASCAT soil moisture over stations that are low irrigated considering that the ASCAT soil moisture has the signature of irrigation effects. The above expectation turns out to be true for four (Rahuri, Pune, Niphad, and Bhopal) of the six stations that have low irrigation values. All the above mentioned four stations have higher RMSE of soil moisture after data assimilation as compared to CNTRL run for the annual average(refer Table 2).

It is certainly true that a small number of stations are showing deviant behavior from the above hypothesis. Sabour a station in Bhagalpur district in the state of Bihar despite being a highly irrigated station has shown a negative impact after data assimilation with a higher RMSE value of soil moisture for the EXP run as compared to the CNTRL run (refer Tables 2 to 6). Similarly, two stations among the moderately irrigated stations (Udaipur and Nagpur) have shown a negative impact after data assimilation. Furthermore, two of the low irrigated stations (Vellanikara and Vittal) have shown a positive impact after data assimilation.

It is clear that a substantial majority of the stations (17 out of 22)have shown a clear positive/negative impact, including no or very small impact, that assimilation of ASCAT soil moisture has impacted positively for most of the stations that have high irrigation and 
or stations that have moderately irrigation while assimilation of ASCAT soil moisture has impacted negatively for most of the stations that have very low irrigation levels. Overall, the above results lead to confirm the notion that the ASCAT soil moisture has the signature of irrigation effects and assimilating the ASCAT soil moisture would invariably lead to an improved soil moisture estimate closer to the ground truth.

13 out of 22 stations show larger values of RMSE of IMDAA soil moisture as compared to the RMSE of both model runs (CNTRL and EXP runs), while for 6 stations the RMSE of IMDAA soil moisture is less than the RMSE of both model runs. For 3 stations, RMSE of IMDAA soil moisture has values intermediate between the RMSE of model runs (higher than CNTRL and lower than EXP). The soil moisture correlation value of IMDAA has lower values for 11 stations (out of 22) and higher values for 7 stations as compared to CNTRL and EXP runs. For 4 stations, IMDAA correlation values are either intermediate or equal to the model runs (CNTRL and EXP). The above results may appear surprising considering that both IMDAA and EXP run have assimilated ASCAT soil moisture observation. However, it is to be noted that the Richardson equation for soil water used in Noah LSM is not a linear partial differential equation since the diffusion term is not linear. It is well known that EnKF data assimilation provides better results as compared to EKF for nonlinear equations. The reason for a majority (13 out of 22) of stations reporting lower CNTRL RMSE soil moisture values as compared to IMDAA RMSE values are somewhat harder to explain. The soil moisture from CNTRL run is obtained by integrating a relatively simple model (Noah LSM) with observed IMD rainfall forcings and realistic surface meteorology from GDAS. However, the IMDAA regional reanalysis utilized the Unified model and employed 4DVAR data assimilation for the atmospheric variables and utilized EKF data assimilation for soil moisture fields. The LSM called Joint UK Land Environment System (JULES) is coupled to the Unified Model and soil moisture analysis is performed by EKF method for IMDAA. While it is indeed surprising that the soil moisture RMSE of CNTRL (without any data assimilation) run has lower RMSE values as compared to RMSE of IMDAA analysis, it has to be noted that rainfall forcing is a very important forcing in the LSM; while in the CNTRL run, the Noah LSM is forced with observed IMD rainfall forcings, the rainfall forcings for the JULES LSM for IMDAA analysis is forced by the model (Unified Model) simulated precipitation. Thus, despite carrying EKF assimilation involving ASCAT soil moisture estimate in IMDAA, due to errors and uncertainties in the model generated rainfall forcings, the soil moisture analysis from IMDAA may show larger RMSE values of soil moisture as compared to RMSE CNTRL values. In general most data assimilation methods such as EnKF and EKF assume that the random error for the model and observations are Gaussian. Also land surface exhibits the following characteristics such as (i) heterogeneity (smaller spatial scale as compared to atmosphere and ocean), (ii) non-linearities, and non- Gaussiality (e.g hydrological cycle) that pose serious challenges while applying data assimilation methods. The above mentioned features of land surface, especially those related to non-linear and non-Guassiality have important implications while applying Kalman filter methods (Lahoz and Schneider, 2014).

The assimilated soil moisture estimate is further evaluated using triple collocation (TC) method. For the TC analysis, two sets of triplet soil moisture data sets have been selected. The GLDAS and MERRA model soil moisture estimates are kept same for both sets of triplets, while the role of the third data set in each of the two triplets is played by soil moisture in the CNTRL run and EXP run. The first set of triplet soil moisture datasets (GLDAS CLSM, MERRA and CNTRL run) will all be devoid of any signature of irrigation effects [Nair and Indu (2019)], However, while the first two of the second set of triplet soil moisture data sets (GLDAS CLSM, MERRA and EXP run) lack any signature of irrigation effects, 
the soil moisture data set obtained from the EXP run has the signature of irrigation effects due to assimilation of ASCAT soil moisture in the EXP run. One would expect that the TC analysis with soil moisture from EXP run will exhibit high errors and low correlations over the irrigated regions [(Kolassa et al., 2017, Nair and Indu, 2019)]. On the contrary, the TC analysis with soil moisture from CNTRL run will exhibit low errors and high correlations over the irrigated regions.

The TC analysis are performed during the winter and pre-monsoon seasons, the months that precede the chief rainfall season over India. The squared correlation coefficient $\left(R^{2}\right)$ is calculated based on the study of McColl et al. (2014). Figures $7 \mathrm{~A}$ and $7 \mathrm{~b}$, depict the squared correlation coefficient $\left(R^{2}\right)$ of the TC analysis of the two sets of triplets that have utilized soil moisture estimates from the CNTRL run and the EXP run for the third data set. Figure 7 e depicts the difference in the squared correlation coefficient $\left(R^{2}\right)$ between the two sets of triplets that employ soil moisture estimates from CNTRL run and EXP run. From figure 7k, it is clear that the assimilated soil moisture simulation shows lower squared correlation coefficient values over highly irrigated areas (refer to figure $7 \mathrm{~d}$ ) as compared to the triplet set that utilizes the soil moisture from the CNTRL run. The lower squared correlation coefficient values of the triplet with EXP run is more manifested and are found to be spatially distributed over the Northwest India region. It is to be noted that, the irrigation regions are also more spatially distributed over these regions [refer to figure $7 \mathrm{~d}$ ]. Over Northeast India, except for the states of Bihar and Jharkhand, the impact of TC analysis is not significant. This is attributed to the fact that the most of the regions in Northeast India are low irrigated regions. However, over the states of Bihar and Jharkhand Figures $7 \mathrm{a}$ and 7 show high squared correlation coefficient $\left(R^{2}\right)$ for the CNTRL run compared to EXP run since the aforementioned states are highly irrigated. Over south Peninsular India, regions over the Western Ghats show no change in squared correlation coefficient after assimilating with ASCAT soil moisture. Over Central India, meteorological subdivisions such as Saurashtra \& Kutch, Gujarat, West Madhya Pradesh, and Chhattisgarh are highly irrigated and the above regions show low squared correlation coefficient values after data assimilation. Further more, the error values in TC analysis are calculated based on fractional root mean square error (fRMSE) as proposed by Draper et al. (2012). Figures $7 \mathrm{e}$ and $7 \mathrm{f}$ show the fRMSE values of the TC analysis associated with the two sets of triplets that employ soil moisture from the CNTRL run and EXP run, respectively. From figures $7 \mathrm{e}$ and $7 \mathrm{f}$, it is clear that the high irrigated areas (refer to Figure $7 \mathrm{~d}$ ) shows high fRMSE values after data assimilation. The above feature of manifestation of high fRMSE values is not prominent over the regions where the irrigation effects are lower. The above discussion conclusively demonstrates that the TC analysis employed in this study effectively captures the signature and importance of irrigation in the soil moisture data set of the EXP run that had assimilated ASCAT soil moisture.

\section{Conclusion}

This study has assimilated the ASCAT near surface soil moisture in the Noah LSM using EnKF data assimilation technique and assessed the impact of assimilation using the forecast impact parameter and improvement parameter over the Indian domain for the year 2012 with respect to IMDAA data. Furthermore, the assimilated soil moisture (EXP run) is validated with IMD in-situ soil moisture stations. The results clearly indicate that 12 of the 22 stations show reduced soil moisture RMSE after data assimilation. Also, 11 of the 22 stations report higher correlation coefficient values of soil moisture after data assimilation. 

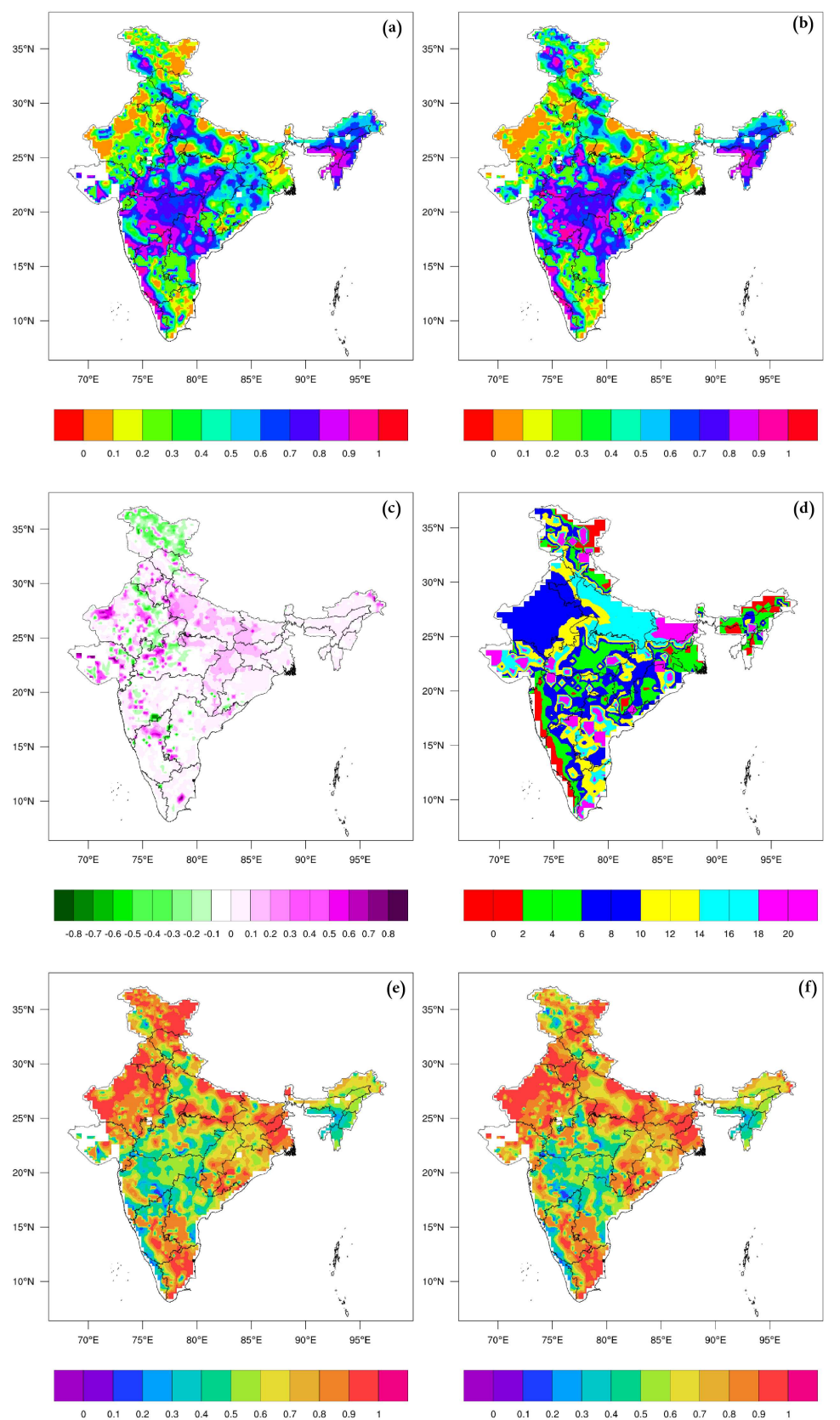

Fig. 7: Depicts the squared correlation coefficient $\left(R^{2}\right)$ from Triple collocation method for (a) CNTRL run and (b) EXP run, (c) the change (CNTRL-EXP) in squared correlation coefficient of CNTRL and EXP run, (d) the irrigation map of India in mm for the year 2012, fractional RMSE of (e)CNTRL run and (f) EXP run using Triple collocation method. 
Table 2: Comparison of soil moisture RMSE and correlation coefficient (R) of CNTRL run, EXP run, and IMDAA at $5 \mathrm{~cm}$ depth at 22 stations for the year 2012.

\begin{tabular}{|c|c|c|c|c|c|c|c|}
\hline No. & Station & $\begin{array}{l}\text { RMSE } \\
\text { (CN- } \\
\text { TRL) } \\
\mathrm{m}^{3} / \mathrm{m}^{3}\end{array}$ & $\begin{array}{l}\text { RMSE } \\
(\mathrm{EXP}) \\
\mathrm{m}^{3} / \mathrm{m}^{3}\end{array}$ & $\begin{array}{l}\text { RMSE } \\
\text { (IM- } \\
\text { DAA) } \\
\mathrm{m}^{3} / \mathrm{m}^{3}\end{array}$ & $\begin{array}{l}\text { R (CN- } \\
\text { TRL) }\end{array}$ & $\begin{array}{l}\mathrm{R} \\
\text { (EXP) }\end{array}$ & $\begin{array}{l}\text { R (IM- } \\
\text { DAA) }\end{array}$ \\
\hline 1 & Basti & 0.036 & 0.032 & 0.100 & 0.90 & 0.90 & 0.77 \\
\hline 2 & Bhubaneswar & 0.100 & 0.096 & 0.142 & 0.85 & 0.87 & 0.84 \\
\hline 3 & Ranchi & 0.168 & 0.164 & 0.203 & 0.76 & 0.73 & 0.60 \\
\hline 4 & Sabour & 0.085 & 0.097 & 0.119 & 0.65 & 0.65 & 0.48 \\
\hline 5 & Chatha & 0.069 & 0.066 & 0.087 & 0.56 & 0.56 & 0.71 \\
\hline 6 & Ludhiana & 0.171 & 0.165 & 0.097 & 0.83 & 0.80 & 0.84 \\
\hline 7 & Karnal & 0.055 & 0.055 & 0.070 & 0.73 & 0.71 & 0.74 \\
\hline 8 & New Delhi & 0.080 & 0.081 & 0.110 & 0.65 & 0.67 & 0.60 \\
\hline 9 & Durgapura & 0.116 & 0.110 & 0.076 & 0.87 & 0.90 & 0.86 \\
\hline 10 & Udaipur & 0.071 & 0.121 & 0.078 & 0.88 & 0.85 & 0.80 \\
\hline 11 & Solapur & 0.073 & 0.061 & 0.087 & 0.86 & 0.89 & 0.61 \\
\hline 12 & Rahuri & 0.055 & 0.063 & 0.147 & 0.56 & 0.64 & 0.32 \\
\hline 13 & Pune & 0.083 & 0.093 & 0.094 & 0.76 & 0.76 & 0.83 \\
\hline 14 & Niphad & 0.051 & 0.056 & 0.141 & 0.78 & 0.82 & 0.68 \\
\hline 15 & Nagpur & 0.091 & 0.120 & 0.104 & 0.75 & 0.72 & 0.75 \\
\hline 16 & Bhopal & 0.078 & 0.109 & 0.080 & 0.79 & 0.64 & 0.73 \\
\hline 17 & Sagar & 0.106 & 0.095 & 0.071 & 0.89 & 0.92 & 0.92 \\
\hline 18 & Bellari & 0.080 & 0.068 & 0.062 & 0.79 & 0.84 & 0.73 \\
\hline 19 & Vellanikara & 0.130 & 0.125 & 0.149 & 0.86 & 0.86 & 0.89 \\
\hline 20 & Vedasundar & 0.166 & 0.152 & 0.074 & 0.37 & 0.42 & 0.68 \\
\hline 21 & Vittal & 0.119 & 0.110 & 0.146 & 0.90 & 0.92 & 0.92 \\
\hline 22 & Anakapalle & 0.061 & 0.068 & 0.016 & 0.81 & 0.82 & 0.85 \\
\hline
\end{tabular}

Since the model output is subjected to errors from atmospheric forcings, initial conditions, model discrepancies, and model deficiencies (such as not incorporating some important effects that are present), the CNTRL run soil moisture overestimates the IMDAA soil moisture. The most significant improvements due to assimilation are found over the western parts of the Central Indian region during the pre-monsoon season that are associated with large negative differences between ASCAT and CNTRL soil moisture values. The above regions experienced lower rainfall rate and have non irrigated croplands over the Central Indian region contributing to reduced overestimation of the CNTRL soil moisture after assimilation. The least improvements of soil moisture due to data assimilation are seen during the monsoon season. Possibly, the irrigation requirements are minimum during the typical rainy season (monsoon season). Most of the stations that are highly irrigated and or moderately irrigated show reduced soil moisture RMSE after assimilation with respect to IMD in-situ data, while majority of the stations that have low irrigation levels show negative impact due to data assimilation showing that the effects of irrigation as reflected in the ASCAT soil moisture data do contribute to improved soil moisture states and hence, significant improvements to incorporate the effect of irrigation in LSMs, may improve the model soil moisture estimates.

The impact of irrigation on assimilated soil moisture is further evaluated using the triple collocation (TC) method. The TC analysis is performed using GLDAS CLSM, and MERRA Land data with EXP and CNTRL run soil moisture estimates as the third data set for each of the two triplets. As the GLDAS CLSM and MERRA data do not have the signature of irrigation, the assimilated soil moisture shows a low correlation coefficient value and high 
Table 3: Same as Table 2 but for Winter season.

\begin{tabular}{|c|c|c|c|c|c|c|c|}
\hline No. & Station & $\begin{array}{l}\text { RMSE } \\
\text { (CN- } \\
\text { TRL) } \\
\mathrm{m}^{3} / \mathrm{m}^{3}\end{array}$ & $\begin{array}{l}\text { RMSE } \\
\text { (EXP) } \\
\mathrm{m}^{3} / \mathrm{m}^{3}\end{array}$ & $\begin{array}{l}\text { RMSE } \\
\text { (IM- } \\
\text { DAA) } \\
\mathrm{m}^{3} / \mathrm{m}^{3}\end{array}$ & $\begin{array}{l}\text { R (CN- } \\
\text { TRL) }\end{array}$ & $\begin{array}{l}\mathrm{R} \\
\text { (EXP) }\end{array}$ & $\begin{array}{l}\text { R (IM- } \\
\text { DAA) }\end{array}$ \\
\hline 1 & Basti & 0.030 & 0.030 & 0.040 & 0.23 & 0.20 & 0.26 \\
\hline 2 & Bhubaneswar & 0.030 & 0.030 & 0.026 & 0.83 & 0.84 & 0.64 \\
\hline 3 & Ranchi & 0.112 & 0.111 & 0.120 & -0.05 & -0.05 & -0.05 \\
\hline 4 & Sabour & 0.036 & 0.056 & 0.070 & 0.86 & 0.87 & 0.71 \\
\hline 5 & Chatha & 0.053 & 0.046 & 0.100 & -0.24 & -0.22 & -0.23 \\
\hline 6 & Ludhiana & 0.152 & 0.154 & 0.110 & 0.70 & 0.69 & 0.67 \\
\hline 7 & Karnal & 0.040 & 0.040 & 0.040 & 0.70 & 0.62 & 0.59 \\
\hline 8 & New Delhi & 0.070 & 0.070 & 0.030 & 0.33 & 0.33 & 0.84 \\
\hline 9 & Durgapura & 0.076 & 0.079 & 0.010 & -0.06 & -0.03 & -0.01 \\
\hline 10 & Udaipur & 0.070 & 0.126 & 0.020 & -0.96 & 0.92 & 0.98 \\
\hline 11 & Solapur & 0.080 & 0.079 & 0.040 & 0.74 & 0.90 & 0.61 \\
\hline 12 & Rahuri & 0.100 & 0.100 & 0.210 & 0.73 & 0.74 & -0.59 \\
\hline 13 & Pune & 0.035 & 0.036 & 0.110 & 0.66 & 0.67 & 0.66 \\
\hline 14 & Niphad & 0.040 & 0.047 & 0.150 & -0.42 & -0.45 & -0.25 \\
\hline 15 & Nagpur & 0.030 & 0.068 & 0.110 & 0.35 & -0.45 & 0.31 \\
\hline 16 & Bhopal & 0.040 & 0.049 & 0.060 & 0.21 & 0.24 & 0.13 \\
\hline 17 & Sagar & 0.070 & 0.068 & 0.050 & 0.96 & 0.97 & 0.95 \\
\hline 18 & Bellari & 0.090 & 0.090 & 0.030 & -0.27 & -0.25 & -0.35 \\
\hline 19 & Vellanikara & 0.120 & 0.130 & 0.090 & 0.96 & 0.96 & 0.94 \\
\hline 20 & Vedasundar & 0.113 & 0.103 & 0.010 & 0.99 & 0.99 & 0.94 \\
\hline 21 & Vittal & 0.090 & 0.090 & 0.040 & 0.93 & 0.93 & 0.93 \\
\hline 22 & Anakapalle & 0.040 & 0.040 & 0.020 & 0.84 & 0.87 & 0.98 \\
\hline
\end{tabular}

fRMSE value over highly irrigated regions. These results indicate that the TC analysis has effectively captured the impact of irrigation on data assimilation.

The land surface characteristics such as land cover and soil texture types are predefined in Noah LSM and the land cover and soil texture types are fixed to a single land cover class and a single soil texture one for each grid point. However, in reality, the above parameters have spatial heterogeneity even within a grid cell. In addition, the variation of the soil texture type with soil depth is also not considered and modelled in the Noah LSM. Furthermore, the one dimensional Noah LSM used in the present study is not adequate to describe the land surface interactions in the horizontal. The Noah LSM can only provide for the vertical variations of soil moisture and soil temperatures over various soil depths. The drained water from the bottom layer removes immediately in Noah LSM, which results in fewer memories of preceding weather and climate changes. Since the Noah model has a shallow soil column, the model is unable to capture the soil critical zone (up to $5 \mathrm{~m}$ depth). The Noah LSM has a combined soil and vegetation surface. Hence, it is difficult to implement the dynamic leaf model in Noah LSM.

\section{ACKNOWLEDGMENT}

The authors thank the Hydrological Sciences Laboratory, at NASA GSFC and NCAR for providing the LIS and the Noah LSM. The authors thank the Director-General of IMD and Head, NCMRWF for providing the IMD in-situ soil moisture and IMDAA data. The first author thanks the CSIR for providing Research fellowship. The authors acknowledge the 
Table 4: Same as Table 2 but for Pre-monsoon season.

\begin{tabular}{|c|c|c|c|c|c|c|c|}
\hline No. & Station & $\begin{array}{l}\text { RMSE } \\
\text { (CN- } \\
\text { TRL) } \\
\mathrm{m}^{3} / \mathrm{m}^{3}\end{array}$ & $\begin{array}{l}\text { RMSE } \\
\text { (EXP) } \\
\mathrm{m}^{3} / \mathrm{m}^{3}\end{array}$ & $\begin{array}{l}\text { RMSE } \\
\text { (IM- } \\
\text { DAA) } \\
\mathrm{m}^{3} / \mathrm{m}^{3}\end{array}$ & $\begin{array}{l}\text { R (CN- } \\
\text { TRL) }\end{array}$ & $\begin{array}{l}\text { R } \\
\text { (EXP) }\end{array}$ & $\begin{array}{l}\text { R (IM- } \\
\text { DAA) }\end{array}$ \\
\hline 1 & Basti & 0.030 & 0.020 & 0.070 & 0.55 & -0.01 & 0.61 \\
\hline 2 & Bhubaneswar & 0.036 & 0.035 & 0.020 & 0.90 & 0.90 & 0.84 \\
\hline 3 & Ranchi & 0.068 & 0.066 & 0.010 & 0.84 & 0.84 & 0.80 \\
\hline 4 & Sabour & 0.044 & 0.066 & 0.090 & 0.035 & -0.13 & -0.35 \\
\hline 5 & Chatha & 0.061 & 0.070 & 0.050 & -0.08 & 0.05 & 0.57 \\
\hline 6 & Ludhiana & 0.166 & 0.123 & 0.020 & 0.61 & 0.38 & 0.77 \\
\hline 7 & Karnal & 0.040 & 0.035 & 0.020 & 0.39 & 0.34 & 0.85 \\
\hline 8 & New Delhi & 0.050 & 0.055 & 0.010 & -0.09 & -0.12 & -0.15 \\
\hline 9 & Durgapura & 0.076 & 0.075 & 0.010 & 0.25 & 0.27 & 0.15 \\
\hline 10 & Udaipur & 0.060 & 0.152 & 0.020 & 0.89 & 0.85 & 0.85 \\
\hline 11 & Solapur & 0.100 & 0.085 & 0.003 & 0.73 & 0.72 & 0.48 \\
\hline 12 & Rahuri & 0.040 & 0.041 & 0.100 & 0.68 & 0.74 & 0.29 \\
\hline 13 & Pune & 0.060 & 0.069 & 0.070 & 0.32 & 0.41 & 0.49 \\
\hline 14 & Niphad & 0.060 & 0.058 & 0.110 & 0.84 & 0.87 & 0.69 \\
\hline 15 & Nagpur & 0.050 & 0.122 & 0.100 & 0.22 & 0.24 & 0.20 \\
\hline 16 & Bhopal & 0.030 & 0.045 & 0.080 & 0.84 & 0.77 & 0.74 \\
\hline 17 & Sagar & 0.100 & 0.089 & 0.020 & 0.03 & -0.07 & 0.18 \\
\hline 18 & Bellari & 0.078 & 0.079 & 0.040 & 0.68 & 0.74 & 0.71 \\
\hline 19 & Vellanikara & 0.100 & 0.088 & 0.100 & 0.82 & 0.83 & 0.84 \\
\hline 20 & Vedasundar & 0.125 & 0.117 & 0.060 & 0.53 & 0.60 & 0.75 \\
\hline 21 & Vittal & 0.080 & 0.076 & 0.060 & 0.81 & 0.82 & 0.87 \\
\hline 22 & Anakapalle & 0.045 & 0.046 & 0.010 & 0.76 & 0.76 & 0.68 \\
\hline
\end{tabular}

Director of IIST for support, encouragement, and computing facility. The authors also thank Dr. Subimal Ghosh and Ms. Anjana Devanand for providing the data to plot Figure $7 \mathrm{~d}$. Finally, the authors thank the anonymous reviewer for the valuable suggestions and comments which have improved the quality of the manuscript.

\section{Funding}

The present study has not received any specific grant or funding from any agency.

\section{Author's Contributions}

While the second author assisted in the design of the study and contributed to interpretation and broad conclusion of the results, the first author contributed in carrying out the detailed model simulations, as well as additional analysis that were carried out. Furthermore, the first author contributed to writing the manuscript.

\section{Availability of data and material}

The data sets and material used in the present study, except for the IMD in-situ soil moisture data are freely available in the web. 
Table 5: Same as Table 2 but for Monsoon season.

\begin{tabular}{llllllll}
\hline No. Station & $\begin{array}{l}\text { RMSE } \\
(\mathrm{CN}- \\
\text { TRL) } \\
\mathrm{m}^{3} / \mathrm{m}^{3}\end{array}$ & $\begin{array}{l}\text { RMSE } \\
(\text { EXP) }\end{array}$ & $\begin{array}{l}\text { RMSE } \\
(\text { IM- } \\
\mathrm{m}^{3} / \mathrm{m}^{3}\end{array}$ & $\begin{array}{l}\text { RAA) } \\
\mathrm{m}^{3} / \mathrm{m}^{3}\end{array}$ & $\begin{array}{l}\text { TRL) } \\
\text { (EXP) }\end{array}$ & $\begin{array}{l}\text { R (IM- } \\
\text { DAA) }\end{array}$ \\
\hline 1 & Basti & 0.048 & 0.044 & 0.110 & 0.76 & 0.79 & 0.68 \\
\hline 2 & Bhubaneswar & 0.134 & 0.132 & 0.220 & 0.79 & 0.79 & 0.83 \\
\hline 3 & Ranchi & 0.250 & 0.240 & 0.350 & -0.26 & -0.26 & -0.20 \\
\hline 4 & Sabour & 0.127 & 0.137 & 0.170 & 0.69 & 0.70 & 0.42 \\
\hline 5 & Chatha & 0.090 & 0.077 & 0.120 & 0.78 & 0.69 & 0.76 \\
\hline 6 & Ludhiana & 0.181 & 0.145 & 0.140 & 0.83 & 0.82 & 0.83 \\
\hline 7 & Karnal & 0.076 & 0.075 & 0.110 & 0.81 & 0.77 & 0.70 \\
\hline 8 & New Delhi & 0.100 & 0.120 & 0.190 & 0.69 & 0.70 & 0.61 \\
\hline 9 & Durgapura & 0.157 & 0.143 & 0.130 & 0.74 & 0.78 & 0.74 \\
\hline 10 & Udaipur & 0.086 & 0.118 & 0.100 & 0.73 & 0.73 & 0.64 \\
\hline 11 & Solapur & 0.079 & 0.070 & 0.100 & 0.84 & 0.91 & 0.43 \\
\hline 12 & Rahuri & 0.030 & 0.033 & 0.120 & 0.50 & 0.54 & 0.35 \\
\hline 13 & Pune & 0.125 & 0.126 & 0.060 & 0.63 & 0.58 & 0.91 \\
\hline 14 & Niphad & 0.050 & 0.053 & 0.160 & 0.80 & 0.79 & 0.67 \\
\hline 15 & Nagpur & 0.136 & 0.139 & 0.110 & 0.54 & 0.63 & 0.58 \\
\hline 16 & Bhopal & 0.110 & 0.125 & 0.090 & 0.71 & 0.68 & 0.65 \\
\hline 17 & Sagar & 0.130 & 0.110 & 0.110 & 0.87 & 0.92 & 0.89 \\
\hline 18 & Bellari & 0.060 & 0.050 & 0.090 & 0.92 & 0.92 & 0.74 \\
\hline 19 & Vellanikara & 0.149 & 0.114 & 0.210 & 0.61 & 0.62 & 0.67 \\
\hline 20 & Vedasundar & 0.220 & 0.200 & 0.070 & 0.36 & 0.43 & 0.85 \\
\hline 21 & Vittal & 0.150 & 0.140 & 0.200 & 0.62 & 0.64 & 0.53 \\
\hline 22 & Anakapalle & 0.070 & 0.072 & 0.020 & 0.60 & 0.64 & 0.56 \\
\hline & & & & & & & \\
\hline
\end{tabular}

\section{Code availability}

The codes employed in this study are available to be shared on request.

\section{Ethics approval}

The authors declare that the contents and the results of the manuscript have not been published in any other journal or conference.

\section{Consent to participate and Consent for publication}

The authors provide their consent and willingness to participate in the publication process and to publish the above manuscript.

\section{Disclosure statement}

No conflict of interest is reported by the authors. 
Table 6: Same as Table 2 but for Post-monsoon season.

\begin{tabular}{|c|c|c|c|c|c|c|c|}
\hline No. & Station & $\begin{array}{l}\text { RMSE } \\
\text { (CN- } \\
\text { TRL) } \\
\mathrm{m}^{3} / \mathrm{m}^{3}\end{array}$ & $\begin{array}{l}\text { RMSE } \\
\text { (EXP) } \\
\mathrm{m}^{3} / \mathrm{m}^{3}\end{array}$ & $\begin{array}{l}\text { RMSE } \\
\text { (IM- } \\
\text { DAA) } \\
\mathrm{m}^{3} / \mathrm{m}^{3}\end{array}$ & $\begin{array}{l}\text { R (CN- } \\
\text { TRL) }\end{array}$ & $\begin{array}{l}\text { R } \\
\text { (EXP) }\end{array}$ & $\begin{array}{l}\text { R (IM- } \\
\text { DAA) }\end{array}$ \\
\hline 1 & Basti & 0.036 & 0.015 & 0.140 & 0.99 & 0.99 & 0.83 \\
\hline 2 & Bhubaneswar & 0.120 & 0.097 & 0.120 & 0.69 & 0.73 & 0.84 \\
\hline 3 & Ranchi & 0.170 & 0.140 & 0.130 & 0.67 & 0.63 & 0.82 \\
\hline 4 & Sabour & 0.080 & 0.080 & 0.090 & 0.06 & 0.08 & -0.07 \\
\hline 5 & Chatha & 0.061 & 0.038 & 0.050 & -0.17 & -0.2 & 0.51 \\
\hline 6 & Ludhiana & 0.182 & 0.147 & 0.020 & 0.25 & 0.34 & -0.31 \\
\hline 7 & Karnal & 0.042 & 0.045 & 0.040 & 0.55 & 0.62 & 0.86 \\
\hline 8 & New Delhi & 0.048 & 0.058 & 0.030 & -0.17 & -0.16 & -0.59 \\
\hline 9 & Durgapura & 0.113 & 0.106 & 0.010 & 0.52 & 0.57 & 0.18 \\
\hline 10 & Udaipur & 0.060 & 0.116 & 0.100 & 0.90 & 0.91 & 0.93 \\
\hline 11 & Solapur & 0.060 & 0.043 & 0.090 & 0.76 & 0.79 & 0.70 \\
\hline 12 & Rahuri & 0.058 & 0.063 & 0.180 & 0.50 & 0.52 & 0.31 \\
\hline 13 & Pune & 0.060 & 0.069 & 0.140 & 0.88 & 0.88 & 0.94 \\
\hline 14 & Niphad & 0.050 & 0.054 & 0.170 & 0.62 & 0.63 & 0.57 \\
\hline 15 & Nagpur & 0.088 & 0.112 & 0.090 & 0.73 & 0.65 & 0.81 \\
\hline 16 & Bhopal & 0.098 & 0.148 & 0.090 & -0.16 & -0.22 & 0.81 \\
\hline 17 & Sagar & 0.100 & 0.090 & 0.050 & 0.69 & 0.71 & 0.68 \\
\hline 18 & Bellari & 0.077 & 0.050 & 0.050 & 0.89 & 0.89 & 0.70 \\
\hline 19 & Vellanikara & 0.158 & 0.118 & 0.170 & 0.89 & 0.89 & 0.88 \\
\hline 20 & Vedasundar & 0.166 & 0.113 & 0.140 & 0.88 & 0.89 & 0.79 \\
\hline 21 & Vittal & 0.120 & 0.119 & 0.180 & 0.94 & 0.95 & 0.93 \\
\hline 22 & Anakapalle & 0.090 & 0.095 & 0.010 & 0.96 & 0.97 & 0.93 \\
\hline
\end{tabular}

Table 7: IMD in-situ stations are tabulated, based on irrigation.

\begin{tabular}{lll}
\hline $\begin{array}{l}\text { Low Irrigated } \\
(6 \mathrm{~mm} \text { or less })\end{array}$ & $\begin{array}{l}\text { Moderately Irrigated } \\
(6 \text { to } 14 \mathrm{~mm})\end{array}$ & $\begin{array}{l}\text { Highly Irrigated } \\
\text { (Above 14 mm) }\end{array}$ \\
\hline Rahuri & Bhubaneswar & Basti \\
Pune & Ludhiana & Sabour \\
Niphad & New Delhi & Ranchi \\
Bhopal & Durgapura & Karnal \\
Vellanikkara & Udaipur & Solapur \\
Vittal & Nagpur & \\
& Sagar & \\
& Bellari & \\
& Chatha & \\
& Vedasundar & \\
& Anakapalle & \\
\hline
\end{tabular}

\section{References}

Ashrit R, Indira Rani S, Kumar S, Karunasagar S, Arulalan T, Francis T, Routray A, Laskar SI, Mahmood S, Jermey P, Maycock A, Renshaw R, George JP, Rajagopal EN (2020) Imdaa regional reanalysis: Performance evaluation during indian summer monsoon season. Journal of Geophysical Research: Atmospheres 125(2):e2019JD030973, DOI 10.1029/2019JD030973 
Blankenship C, Case J, Zavodsky B, Crosson W (2016) Assimilation of smos retrievals in the land information system. IEEE Transactions on Geoscience and Remote Sensing 54:1-13, DOI 10.1109/TGRS.2016.2579604

Case JL, LaCasse KM, Santanello JA, Lapenta WM, Peters-Lidard CD (2007) Improved modeling of landatmosphere interactions using a coupled version of wrf with the land information system. In: 21st Conf. on Hydrology, San Antonio, TX, Amer. Meteor. Soc., 5A.4

Chakravarty IM, Laha RG, Roy JD (1967) Handbook of methods of applied statistics. McGraw-Hill, New York, NY, URL https://cds . cern.ch/record/109749

Chen F, Dudhia J (2001) Coupling an advanced land surfacehydrology model with the penn statencar mm5 modeling system. part i: Model implementation and sensitivity. Monthly Weather Review 129:569-585, DOI 10.1175/1520-0493(2001)129〈0569:CAALSH $\rangle 2.0$. $\mathrm{CO} ; 2$

Chen F, Mitchell K, Schaake J, Xue Y, Pan HL, Koren V, Duan QY, Ek M, Betts A (1996) Modeling of land surface evaporation by four schemes and comparison with fife observations. Journal of Geophysical Research: Atmospheres 101(D3):7251-7268

Devanand A, Huang M, Ashfaq M, Barik B, Ghosh S (2019) Choice of irrigation water management practice affects indian summer monsoon rainfall and its extremes. Geophysical Research Letters 46(15):9126-9135, DOI 10.1029/2019GL083875

Dorigo W, W W, Hohensinn R, Hahn S, Paulik C, Drusch M, S M, Oevelen P, A R, Jackson $\mathrm{T}$ (2011) The international soil moisture network: A data hosting facility for global in situ soil moisture measurements. Hydrology and Earth System Sciences Discussions 15, DOI 10.5194/hessd-8-1609-2011

Draper CS, Reichle RH, De Lannoy GJM, Liu Q (2012) Assimilation of passive and active microwave soil moisture retrievals. Geophysical Research Letters 39(4), DOI 10.1029/ 2011GL050655

Drusch M (2007) Initializing numerical weather prediction models with satellite-derived surface soil moisture: Data assimilation experiments with ecmwf's integrated forecast system and the tmi soil moisture data set. Journal of Geophysical Research: Atmospheres 112(D3), DOI 10.1029/2006JD007478

Gentemann CL (2014) Three way validation of modis and amsr-e sea surface temperatures. Journal of Geophysical Research: Oceans 119(4):2583-2598, DOI 10.1002/ 2013JC009716

Jacquemin B, Noilhan J (1990) Sensitivity study and validation of a land surface parametrization using the hapex-mobilihy data set. Boundary-Layer Meteorology 52:93134, DOI 10.1007/BF00123180

Kaur S, Purohit M (2013) Rainfall statistics of india-2012. Indian Meteorological Department, Hydromet Division, New Delhi Report No. :ESSO /IMD /HS / R.F. REP / 02 (2013) / 16

Kolassa J, Gentine P, Prigent C, Aires F, Alemohammad S (2017) Soil moisture retrieval from AMSR-E and ASCAT microwave observation synergy. part 2: Product evaluation. Remote Sensing of Environment 195:202-217, DOI 10.1016/j.rse.2017.04.020

Krishnankutty Ambika A, Wardlow B, Mishra V (2016) Remotely sensed high resolution irrigated area mapping in india for 2000 to 2015. Scientific Data 3:160118, DOI 10.1038/ sdata.2016.118

Kumar S, Peters-Lidard C, Tian Y, Houser P, Geiger J, Olden S, Lighty L, Eastman J, Doty B, Dirmeyer P, Adams J, Mitchell K, Wood E, Sheffield J (2006) Land information system: An interoperable framework for high resolution land surface modeling. Environmental Modelling \& Software 21(10):1402 - 1415, DOI https://doi.org/10.1016/j.envsoft.2005. 
07.004

Kumar S, Peters-Lidard C, Santanello J, Reichle R, Draper C, Koster R, Nearing G, Jasinski M (2015) Evaluating the utility of satellite soil moisture retrievals over irrigated areas and the ability of land data assimilation methods to correct for unmodeled processes. Hydrology and Earth System Sciences 19, DOI 10.5194/hess-19-4463-2015

Kumar SV, Peters-Lidard CD, Santanello JA, Reichle RH, Draper CS, Koster RD, Nearing G, Jasinski MF (2015) Evaluating the utility of satellite soil moisture retrievals over irrigated areas and the ability of land data assimilation methods to correct for unmodeled processes. Hydrology and Earth System Sciences 19(11):4463-4478, DOI 10.5194/hess-19-4463-2015

Lahoz WA, Schneider P (2014) Data assimilation: making sense of earth observation. Frontiers in Environmental Science 2:16, DOI 10.3389/fenvs.2014.00016

Liu Y, Dorigo W, Parinussa R, de Jeu R, Wagner W, McCabe M, Evans J, van Dijk A (2012) Trend-preserving blending of passive and active microwave soil moisture retrievals. Remote Sensing of Environment 123:280 - 297, DOI https://doi.org/10.1016/j.rse.2012.03. 014

Mahrt L, Ek M (1984) The influence of atmospheric stability on potential evaporation. Journal of Applied Meteorology - J APPL METEOROL 23:222-234, DOI 10.1175/ 1520-0450(1984)023 $\langle 0222:$ TIOASO $\rangle 2.0 . C O ; 2$

Mahrt L, Pan H (1984) A 2-layer model of soil hydrology. Boundary-Layer Meteorology 29:1-20, DOI 10.1007/BF00119116

McColl KA, Vogelzang J, Konings AG, Entekhabi D, Piles M, Stoffelen A (2014) Extended triple collocation: Estimating errors and correlation coefficients with respect to an unknown target. Geophysical Research Letters 41(17):6229-6236, DOI 10.1002/ 2014GL061322

Mitchell KE, Lohmann D, Houser PR, Wood EF, Schaake JC, Robock A, Cosgrove BA, Sheffield J, Duan Q, Luo L, Higgins RW, Pinker RT, Tarpley JD, Lettenmaier DP, Marshall CH, Entin JK, Pan M, Shi W, Koren V, Meng J, Ramsay BH, Bailey AA (2004) The multi-institution north american land data assimilation system (nldas): Utilizing multiple gcip products and partners in a continental distributed hydrological modeling system. Journal of Geophysical Research: Atmospheres 109(D7), DOI 10.1029/2003JD003823

Nair A, Indu J (2019) Improvement of land surface model simulations over india via data assimilation of satellite-based soil moisture products. Journal of Hydrology 573:406-421, DOI 10.1016/j.jhydrol.2019.03.088

Nair AS, Indu J (2016) Enhancing noah land surface model prediction skill over indian subcontinent by assimilating smops blended soil moisture. Remote Sensing 8(12), DOI $10.3390 / \mathrm{rs} 8120976$

Noilhan J, Planton S (1989) A simple parameterization of land surface processes for meteorological models. Monthly Weather Review 117:536-, DOI 10.1175/1520-0493(1989) 117 $\langle 0536$ :ASPOLS $\rangle 2.0 . \mathrm{CO} ; 2$

O'Carroll A, Eyre J, Saunders R (2007) Three-way error analysis between aatsr, amsr-e and in situ sea surface temperature observations. European Space Agency, (Special Publication) ESA SP

Pan H, Mahrt L (1987) Interaction between soil hydrology and boundary-layer development. Boundary-Layer Meteorology 38:185-202

Reichle RH, Koster RD (2004) Bias reduction in short records of satellite soil moisture. Geophysical Research Letters 31(19), DOI 10.1029/2004GL020938

Reichle RH, McLaughlin DB, Entekhabi D (2002) Hydrologic data assimilation with the ensemble kalman filter. Monthly Weather Review 130(1):103-114, DOI 10.1175/ 
1520-0493(2002)

Robinson D, Campbell C, Hopmans J, Hornbuckle B, Jones S, Knight R, Ogden F, Selker J, Wendroth O (2008) Soil moisture measurement for ecological and hydrological watershed-scale observatories: A review. Vadose Zone Journal - VADOSE ZONE J 7, DOI 10.2136/vzj2007.0143

Rodell M, Houser PR, Berg AA, Famiglietti JS (2005) Evaluation of 10 methods for initializing a land surface model. Journal of Hydrometeorology 6(2):146-155, DOI 10.1175/JHM414.1

Srinivasan G, Robock A, Entin JK, Luo L, Vinnikov KY, Viterbo P (2000) Soil moisture simulations in revised amip models. Journal of Geophysical Research: Atmospheres 105(D21):26635-26644, DOI 10.1029/2000JD900443

Stoffelen A (1998) Toward the true near-surface wind speed: Error modeling and calibration using triple collocation. Journal of Geophysical Research: Oceans 103(C4):7755-7766, DOI 10.1029/97JC03180

Walker JP, Houser PR (2001) A methodology for initializing soil moisture in a global climate model: Assimilation of near-surface soil moisture observations. Journal of Geophysical Research: Atmospheres 106(D11):11761-11774, DOI 10.1029/2001JD900149

Yin J, Zhan X, Zheng Y, Liu J, Fang L, Hain CR (2015) Enhancing Model Skill by Assimilating SMOPS Blended Soil Moisture Product into Noah Land Surface Model. Journal of Hydrometeorology 16(2):917-931, DOI 10.1175/JHM-D-14-0070.1

Zhang X, Qiu J, Leng G, Yang Y, Gao Q, Fan Y, Luo J (2018) The potential utility of satellite soil moisture retrievals for detecting irrigation patterns in china. Water 10(11), DOI 10.3390/w10111505 